\title{
The Role of Art Education Teachers' in Developing Emotional Awareness of Students
}

\author{
Dr. Abdelsalam Fahad Al-Awamrah \\ The University of Jordan
}

Yasmin Sameer Shalan

The Ministry of Education

\begin{abstract}
The study aimed to know the role of technical education teachers in developing the emotional awareness of students in Jordanian government schools for the academic year (2019/2020), and the study used the descriptive analytical approach, and the sample consisted of (450) and retrieved (430) students, the results reached The presence of individual differences in the levels of emotional awareness in favor of the female category with an average arithmetic (3.74) higher compared to males with an average arithmetic (3.57), and the study recommended taking into account the need to take care of programs and course of art education through effective educational plans because of its impact on stimulating and raising the degree of awareness of educated people , trained both teacher and students to develop their artistic and technical skills by using technology in their studies and majors to keep pace with modernity and the most prominent techniques in the field of arts, and to pay attention to the issue of stimulating productivity of students and teachers together by setting a list of productive quality criteria that contribute to the preparation and production of artists of different branches of their technical majors.
\end{abstract}

Keywords: Art Education Teachers, Emotional Awareness.

DOI: $10.7176 / \mathrm{JEP} / 11-5-13$

Publication date: February 29th 2020

\section{Introduction}

All societies have a large flow of knowledge, as an inevitable consequence of scientific, technological and technical revolutions that are increasing day by day in various areas of life, which requires individuals to deal with and invest in them to develop their capabilities and capabilities, which will ultimately qualify them towards acquiring the sound scientific foundations of knowledge in addition to developing their capabilities and developing their competence and skills. Of all kinds, such as intellectual, mental, psychological, technical ... etc, which leads towards improving their experiences and reflecting them in their life practices and the practical environment as a kind of response to life changes and development requirements and harm The personal and professional development times regardless of whether these changes are on the quantitative or qualitative level.

Qarni (2017), claims that during answering the questions that arise about the nature of the changes taking place in societies: (Is it advancement and progress or development and change?), It must be said that "the consistent position in talking about change and development instead of advancement and progress, not for nothing but Because the first two concepts are neutral and descriptive, while the last two are "discretionary" and preferential concepts. That is what happened is really huge and quantitative changes in most fields of human life, which take to move from a phase into another phase, so we can say that it develops in terms of exercising mental capabilities and some of those physical, while increasing its tools as an unparalleled increase across the stages of development, and In terms of reaching its knowledge, on everything in the world, on the approximation, degrees of wealth, accuracy, inclusiveness and organization, at this or that culture, degrees with which each new degree emerges, including the previous ones, with a clear prominence. As for progress and advancement, their criteria should be In terms of purposes, not in terms of means (ways) and in the field of what is human, positive and not negative, and in terms of real approach to the ideal of perfection in human behavior and activity in their various forms "(Qarni, 2017, p. 358). 
In order to ensure the importance of keeping abreast of developments in various fields, especially the field of education, so that attention must be paid to the elements of the educational process and its continuous development such as (curriculum - teacher - learner / student - education environment - educational process), the curriculum must have a process of technical, planning and organization in order to get benefits of Its content by students to be properly perceived by teacher on the one hand, and on the other hand, the art education course is a part of the educational curriculum as it is considered an important course that is entered in one way or another in various other courses as it is an illustrative and representative means that affects and is affected by it, it is also working to develop awareness of students in the education environment (Al-Fahdawi, 2008).

Abdel-Hamid (1999) explains that whoever wants to understand and study art education according to its fundamental method, he must have a study of aesthetic experience and aesthetic preference in order to create the aesthetic awareness for the learner, which gives him later the ability to judge the positions and art works, their knowledge, knowledge of their roots, criticize and savoring them.

It is important mentioning that the artistic position and the aesthetic experience require from the recipient to reach a high degree of aesthetic pleasure, which is the very sense of art that pleasure in the soul during watching an artwork, thus tasting or savoring it and sensing its beauty, and this happens through its connection with the emotions of the recipient, which is a special kind of taste related to pure mental research towards a subject or artistic work and not for any other purpose, in other words, which means that the aesthetic experience creates a physical link with the recipient to become a captive of this aesthetic subject and interact with him involuntarily and then realize it "because sensuality in its reality means the presence of aesthetic pleasure included in perception itself, as it means that this pleasure causes resonance throughout the body "(Jarrar, 2016).

The teacher of art education plays a prominent and vital role in developing the aesthetic awareness of the learner, as it is a compass that helps him to develop his awareness and perceptions in general and direct his performance towards a sound destination that will enable him to acquire the appropriate experiences (cognitive, emotional and skill) and the way in which the process of learning and education will be achieved. Therefore, and by relying on a realistic scientific fundamentals and an organized reference frame that enables the learner in the future to rely on it to judge the various issues, attitudes and things surrounding him, in addition to developing and taking into account his sense of taste or savoring towards it to issue the appropriate decision towards the places and various events (Yousef, 2013).

Based on the importance of professional development of the teacher as an important priority of the educational system that is indispensable in an era when scientific, technical, technical and technological development has affected the role of teachers in general and teachers of art education in particular, due to the qualitative change in its role in employment, that has moved from being a lecturer and instructor in the educational process on the knowledge side to a facilitator and actual/active organizer on the emotional / sensory side on the one hand and the executive side on the other hand in order to become a skilled practitioner of technical works through his participation and interaction with students in the education process which Led to the upgrading of his job performance so that he becomes a productive and active person in the professional environment and society, and a catalyst for students to contribute at the productivity also to achieve growth and development on various dimensions such as ; cognitive, intellectual, emotional and artistic skills at the same time (Nuseirat, 2017).

Khouzam (2000) believes that awareness is that "individuals are aware to some degree, at any time, about what is going on inside / outside of themselves. They often are aware of a set of thoughts, feelings, imaginations, memories and perceptions", people have tried since ancient times experimenting several methods of creating awareness, such as singing, circling in a circle, fasting, observing the position of rapid breathing, or fixing focus on things or even through various drugs ... etc., psychologists have many ways in determining what are the properties and facts of consciousness. Some of them focused on the primary processes of awareness by describing individuals and their feelings by looking carefully at their interior, while the other section was directed towards studying mental processes, and the matter of observing consciousness and measuring it which was a very difficult topic in the period between (1950-1930), due to the focusing of their efforts towards studying two topics: stimuli and reactions without paying attention and shedding light on what is going on and happening inside the human from activities that linking what is between them . There are many types of awareness that have different forms and properties, but they ultimately start from a specific type of awareness, which is the usual awakened consciousness or the so-called mental awareness in the moment of awakening, and the other type is awareness in the following cases: (sleep - hypnosis and suggestive - focused meditation abuse), then there is the awareness that occurs when death approaches. 
According to the importance of the role of art education teachers in developing awareness of students, especially in emotional awareness, it must be noted that the art education course differs from all other educational courses in terms of mechanisms and strategies that followed by the teacher in practicing it in order to teach their content to students or even in terms of preparing the learner to deal with it, it is not a framed or written language; that is, it does not take a specific or fixed form as is the case with the formed language, in addition to its purely emotional content which means that it is an influential nature when dealing with it, which requires the teacher and the learner to have a sensitive intrusion towards it, due to its philosophy that goes beyond its approach with the constructive knowledge of its concepts, structures and potentials, to extend to the intuition that enables the learner to organize and link the separated knowledge and facts and their awareness based on their experimental experimentation, thus added to them value and meaning and providing them with emotional effects through the learner's control of possessions to add touches and creative abilities when practicing it, and extracting its potential energy to produce valuable artistic works that require awareness of it and how to perceive it. Sensory and mental perception (Al-Fahdawi, 2008).

It is noticeable that cognition is the actual indicator of the completion of the awareness stage of the learner, and therefore awareness is divided into several types, which are: cognitive awareness - emotional awareness - and skill awareness ... etc., and the most important types of awareness for art education as a key input for its awareness and awareness of the two beauty issues is aesthetic awareness, as it is responsible for / the basic of developing the learner's sense of humor.

Shakshak (2012) states that the nature of the sensation according to the structural theory is a sensory component that does not accept analysis or interpretation, but it is perceptible when a sensory organ is stimulated by an stimulus, internal or external, and the feeling according to functional theory it reflects a changing sensory activity that is expressed by to create a process of awareness of stimuli or perceptions, internal or external to different by senses that capture certain sensory data that is delivered to the central nervous system via neurotransmitters and which it transmits from the sense organ to reach the brain, which in turn gives it a specific coding or cognitive meaning, then it accompanies the process Sensation Q A process of awareness then cognitive and sentimental awareness occurs.

Al-Azazi (2018) expresses that emotional maturity is the primary source on which the other components of emotional intelligence are based, through the amount of emotional energy the learner has that emanates from the ego's behavior that makes him adapt to the conditions, pressures, frustrations, conflicts ... etc. and that whenever he can work on Increasing that energy whenever he invested himself better and managed to manage his attitudes and relationships and develop his talents and abilities in all fields, and emotional maturity by (self-awareness, self-direction, self-esteem, flexibility, motivation to achieve and endure stress) according to Samia Al-Qattan model of emotional intelligence.

Khawaldeh (2018) shows that the concept of emotional awareness in order to be aware of its sound image that enables the learner to self-organize his experiences, especially the emotional ones, it is necessary to know the roots and how it happened, which was summed up by the philosopher Socrates with his famous saying: "Know yourself", that he intended the learner should be on the degree of awareness of himself ; in terms of his feelings and emotions when they happen, which will generate his consciousness, recognizing that the person is responsible for activating them are the two levels of attention and awareness of his moods, inclinations and emotions on the one hand, and on the other hand, the learner's clear awareness of his emotions as the main determinant of his personality trait, which would give him a good degree of control and control of his reactions of different life situations, in addition to making him more able to control his mood in his worst cases, as he would be able to control his emotions and deal consciously with his feelings; so he would not spend as a protect from the danger of transforming into an excessively emotional or capricious individual and mood that would lose him control of himself and the situation as a whole, which leads to a worsening role of motivation and decreasing the value of emotional awareness.

According to Gulman, note that emotion, "refers to certain feelings that are accompanied by specific thoughts about a psychological and biological state and varying preparations for behavior" (Pam Robins, Jean Scott, 2000, p. 72).

It is noted as previously mentioned that there are several differences between the concepts related to emotional awareness or rather those that lead to it; the "feeling" is related to the individual himself; which means it is "internal within" so that it is not accompanied by any apparent expression in front of others, and is stimulated by the stimuli associated with the various "topics" among them are "beauty issues /topics" due to their association with the field of artistic taste/savor, and when "sensation" is stimulated, it will generate a tangible effect such as 
a reflection of it through external emotion indicating it, or an apparent expression, then it will be called "feeling" so it will be called "Self-externally," and it should be said that all human beings share the same types of feelings, but they differ among them in terms of the degree of intensity and being affected by them. If the "feeling and emotion together" have the same path in a consistent line with the individual himself, then "emotion" is formed at that moment and it will be an "individual- self", as the raw material of emotion is "feeling and emotion together" and if individuals unanimously agree on an emotion, whether through a direct or indirect relationship between the involved parties, then it will be called "the conscience" so that the conscience becomes a common and shared feeling by everyone, and therefore it must be noted what it means of these two concepts: (internally - and subjectively). The first is from the individual himself and not are inspired by anyone, while the second is concerned with the nature and quality of the stimulus that drives the sensation of one individual over another.

Hence the role of art education teachers' in its essence considered as the basic pillar on which the learner relies on honing his talents, skills and abilities, which gives him cognitive, effective and sensory experience that enables him to continuously develop his awareness, and it must be recognized that the investment of the educational system of/for art education teachers leads towards the development of their performance and Learners' performance at the same time, and that is based on what they hold of advantages related to their knowledge, capabilities and skills, and thus, in the educational process, masterfully and professionally, and this in turn guarantees and gives them the process of developing emotional awareness among students to achieve high and complementary performance in achieving the work entrusted to them, which leads the educational institutions.

In order to make it adopt a strategy of modeling the competencies of teachers and imitating them and their capabilities to move the rudder of change and directing it upwards towards positive in order to achieve the desired goals at the level of the institution, society and individuals themselves, which will achieve satisfaction and raise the aesthetic sense and taste/savor for all.

\section{The Problem of the Study and its questions:}

The problem of the study is to identify the role of teachers' of art education in developing the emotional awareness of students, which leads them towards making change and development at various levels to them; cognitive, emotional and skillful, especially as the current era is full of cognitive, scientific, technical and technical revolutions and the escalating developments that require an appropriate response in keeping pace with its accurate and fast and achievement, taking into account the importance of devoting effective policies and working mechanisms that increase the degree of individual performance and their adoption of a scientific and practical methodological philosophy that capable of bridging the gap between the current and hoped-for roles In response to all developments in various fields, especially the technical fields, which in turn emphasizes the importance of developing the role of education teachers in Jordanian schools and investing them by relying on their scientific, technical, psychological, social, social, and mental qualifications and qualifications that resulting efficiency and commitment to the ethics and standards of the profession and its positive behaviors emanating from them that ensure them achieving the desired development in providing learners with the necessary experiences, and many studies have confirmed the effectiveness of professional development for teachers and the consequent positive results for them, thus their contribution to the process of developing Consciousness among learners and among these studies is the study of (Al-Hindi, 2011), (Abu Fakhr, 2012), (AlKarkhi, 2015), (Al-Zahrani, 2017), and (Al-Qanasheh, 2019), which emphasize the importance of developing their skills and knowledge that nurtures the intellectual side, which in turn nurtures the emotional awareness of them, which enables them to control their emotions, and therefore the study seeks to answer the following questions:

1. What is the role of art education teachers' in developing emotional awareness of students from the viewpoint of the students themselves?

2. Are there any statistically significant differences at the level of significance $(5=0.05)$ in the role of art education teachers' in developing emotional awareness of students due to gender, classroom variables?

\section{Purpose of the study:}

The study aims to know the role of art education teachers' in developing emotional awareness of students, and to determine the degree of difference between the roles of teachers of art education in developing emotional 
awareness of students according to gender variables (male, female), and academic grade (eighth grade, ninth grade, tenth grade) .

\section{The significance of the Study :}

The importance of the study lies on the importance of its topic / subject as the role of art education teachers in developing the emotional awareness of students that will reflect its impact on them and on their efficiency, performance and knowledge in the near future, which strengthens and raises the percentage of performance and productivity for them thus spreading the culture of creativity, production, participatory and cooperation between

The learners in Jordanian schools, which will eventually lead to improve their knowledge system, their performance, skills and productivity, thus raising their awareness level. The importance of the study highlights the importance of the results that the study seeks to achieve, as follows:

1. Contributing in developing the emotional awareness of students to achieve effective performance that enables students to invest their experiments, knowledge and skills with high efficiency, and to gain deep experience, and to ensure the escalation of their educational path, and reaching the stage of innovation, creativity, production and participatory in the practices of various technical activities.

2. Upgrading and improving the art education teachers, imitating them, enabling them to work and modeling them as scientific and professional competencies at the same time.

3. Providing the educational system with the appropriate mechanisms to develop aesthetic awareness that would contribute at achieving a qualitative shift in the level of performance and upgrading / improving the aesthetic taste/savor of students and converting them from individuals who are consuming knowledge and arts to their producers.

4. Contributing at complementarities, participatory and cooperation levels in the development process between the educational system and various other sectors (political, economic, social, cultural, and media) and the necessity of activating the spreading awareness about the importance of developing aesthetic awareness and artistic sense among members of society, which reflects its impact on its advancement and progress.

5. Make recommendations on mechanisms for developing the role of art education teachers to enable them to develop emotional awareness of students in Jordanian schools and to improve them to get the stage of enlightenment and bring them to a high degree of intellectual stability, knowledge achievement, emotional balance and effective skill performance.

\section{The limits of the study:}

The study limits are represented by the students of the Jordanian government schools; primary level students (eighth, ninth and tenth grade), during the academic year (2020/2019).

\section{Terminology (concepts) of study:}

- Role: "The set of related activities or behavioral frameworks that achieve what is expected in certain situations, and the roles result in the ability to predict the behavior of the individual in different situations" (Morsi, 2001, p. 139).

-Development: "It is the studied growth on scientific basics, the dimensions of which are measured by scientific measures, whether it is comprehensive and integrated development or development in one of the main fields such as the economic, social or political field or sub-fields such as industrial or agricultural development ... etc." (Al-Essawi, 1997 (Pp. 51-50).

"It is the scientific mobilization that is planned for a group of social and economic processes through a specific ideology to achieve the targeted change in order to move from an undesirable state to one that is to be reached" (Al-Issawi, 1997, p. 51).

-Consciousness: "Consciousness has many meanings. We use the word to refer to the total alert of a person or a regular state of alert. Cases of consciousness other than the normal state of alert are considered unconscious states of consciousness and these states can occur naturally (for example during sleep or illness) or intentionally" (Khuzam : According to Linda Davidov, p. 75, 2000). 
The conscience: "The linguistic origin (root) of the emotion (Emotions), which belongs to the Latin word which means (movement), i.e. movement or excitement until it reaches agitation or turmoil, then it refers to strong visceral feelings and then it contradicts the criterion of the logical thoughts and control Khawaldeh, 2018, p. 30).

\section{Previous studies:}

\section{Arab Studies:}

The study of Al-Hindi (2011) aimed to know the effect of using dramatic play in developing emotional intelligence skills in pre-school, and the sample consisted of (90) children from the ages of (6-5) divided into three groups; the first experimental group applied a traditionally program, the second experimental group applied the program through the computer, while the control group did not apply any program, the man drawing test, the emotional intelligence scale and the emotional intelligence development program were used, and the results concluded that there were statistically significant differences between the (tribal - dimensional - consecutive) measurement or processing variable (first experimental - experimental A second - control) in learning cognitive skills and its impact/effect on developing self-awareness and dealing with emotional aspects.

The Abu Fakhr study (2012) in Syria aimed to identify the quality of the art education teacher preparation system in the light of the National Association for Art Education (NAEA) standards from the viewpoint of faculty members and students in the technical education institutes in Damascus, Aleppo, and Black, the study used the descriptive analytical approach, two tools were designed for the study, the first sample included (85) faculty members and the second (409) teacher students, and the study found a weakness in the quality of performance for teachers of Fine Art Education in light of the standards of the National Association for Art Education, and the study recommended the need to intensify practical education and focus on the elves Field to make way for the teacher to practice more creative and innovative artistic activities in the classroom.

Al-Karkhi (2015) study aimed to know the effect of two methods of (reality therapy) and (self-talk) which guiding cognitive in developing the emotional feeling of preparatory students through setting hypotheses for each method and experimenting with experimental and controlling groups, where the researcher built a sentimental sense scale according to the Glasser theory - of treatment with reality, a sample of (600) female students was selected from the preparatory stage, and the indicative intervention was applied on the method of treatment with reality and self-talk. The researcher applied the scale to a sample that was formed from (200) female -students to recognize the degree of low emotional feeling for female students with low emotional feeling according to the results, which preceded it through two experimental groups and control, and the experimental sample consisted of (30) students randomly over the three groups, and after conducting the indicative overlap of the two experimental groups, the post-test was applied using the sentimental sense scale, and the results of the "treatment with reality" method showed a significant impact on the sentimental feeling of students , while the second method, "self-talk", also had a significant impact on the development of conscience. The study recommended the importance of educational counselors to train by cognitive methods that develop emotional feelings, including the two methods of study, that considered as a major component of the components of personal growth and development.

Al-Zahrani study (2017) aimed to know the effect of web applications on developing criticism and technical taste/savoring skills among middle school students' in Al-Baha region, as well as to identify the form of an interactive environment which is necessary for web applications to develop those skills, then to identify the impact of these applications in developing those skills, and the curriculum was used the descriptive, and the experimental approach to achieving the goals of the study. The study sample consisted of (40) middle-school students in the Al-Baha region in the Kingdom of Saudi Arabia, which divided into two experimental groups, one of which is experimental (20) students, and the other is control (20) students. The experimental group exposed to web applications 2.0 While the control group did not receive any application on the web, it was taught in the traditional way and then used the (T) test to measure the significance of the differences between the two study groups and then use the effect size equation to identify the size of the indication that emerged from the application whether that indication is large, medium or small, according to the application, the researcher got the results that there is a statistically significant difference at the level of $(0.05)$ between the mean scores of the members of the experimental group, and the degrees of the control group in the post-application of the test achievement for the analysis and technical criticism in favor of the experimental group, and DBAE that found a statistically difference at the level of (0.05) between the average score for the experimental group members, and the score for the control group in the post-application of the observation card to read the technical works and their taste for the benefit of the experimental group, and one of the most important recommendations that the 
study indicated is the need to use web 2.0 applications to support the various activities in the art education course within the organizational direction (DBAE), And expand its application, and train teachers on it and provide them with the latest developments. Also, enhancing student self-censorship, and employing web applications in knowledge exchange, and practical technical education according to the organizational direction (DBAE).

Al- Ahmadi study (2018) aimed to know the effect of using an electronic bag to develop some skills of teaching artistic education by primary school teachers in the light of formal education, the study used the semiexperimental approach based on the design of one group, and an electronic educational bag was prepared for some skills of teaching art education in the light of the organizational theory, the sample consisted of (34) female teachers of art education who are not specialized in teaching skills of art education, and the results concluded that there is a significant impact on their performance when an e-learning bag is available to give them additional skills in art production, and the study is had number of recommendations, including the necessity of providing e-learning bags for art education in order to develop performance skills of female teachers.

The study of Al-Qamash (2019) at Umm Al-Qura University in Saudi Arabia aimed to define aesthetics in the curriculum of organizational technical education (DBAE) and its classroom practice, the historical descriptive approach was used, and the study concluded that there are three elements that enhance the objectives of the art education curriculum namely training of teachers during service In the field of aesthetics, the development of teacher preparation programs, and the do a lot of studies dealing with aesthetics. Among the results of the study was the emergence of the need for a research revolution in the field of aesthetics by academics and training of teachers in modern programs of contemporary art.

\section{Foreign studies:}

The Sulzer (1998) study in the United States of America aimed to develop the self-efficacy of new art education teachers, by analyzing and identifying training means and needs which through it developing their professional effectiveness, and the study used the descriptive analytical approach, in Florida a sample of the new teachers, and the study concluded that the new teachers should be trained in educational skills and teaching methods in order to increase their professional effectiveness and prepare training programs that enable them to develop their performance.

Lind's study (2007) in the United States of America aimed to identify the quality of professional development by revealing the enhancements and obstacles of professional development in art education in accordance with the principle of cooperative learning to support the teacher and learner in the field of arts and expanding their performance standards and knowledge in the visual arts, and the sample consisted of (57) male and female teachers, the study used the descriptive analytical method, while the study tools were represented by a corresponding card and a note card, and get the effectiveness of the professional development program in its development of the teacher performance, while the obstacles were represented in the limited time period allocated to the program.

The Bahia study (2009) aimed to define the characteristics of teacher education in the field of arts and humanities, specifically arts teachers (plastic arts education and musical education) and humanities teachers (history, geography, and language sciences), the study used the descriptive analytical approach, and the sample was formed The randomness of (46) male and female teachers, also the study concluded that the curriculum should include the aesthetics and creative and critical thinking skills in order to support the thinking process and make it more flexible for them in facing contemporary challenges and developments.

The Shia study (2013) aimed to know the relationship between meta-cognitive awareness and both internal and external motivation among students of the University of Welling College of Arts, and the sample consisted of (81) male and female students, and the study used two measures, one for meta-cognitive awareness and the second for motivation ( Internal / external), the study found a positive relationship between them, and about what this study is, it is worth saying that it focused on self-directed learning in addition to taking into account the importance of supporting development programs, especially in the areas of taste/savor and art criticism.

\section{Summary of previous studies (literature review) and the position of the current study, including:}

Previous studies generally aimed at identifying the role of art education teachers in developing emotional awareness of students, studies used different samples from various Arab and foreign countries; part of which selected a sample of teachers, others used a sample of students, and for the current study it aims to identify the 
role of art education teachers in developing emotional awareness of students in the Jordanian public schools, and they agreed with some of the previous studies, including the studies of (Sulzer, 1998), (Lind, 2007), (Chia, 2013), (Al-Hindi, 2011), (Al-Karkhi, 2015), (Al-Zahrani, 2017), and (Al-Qanash, 2019), and they differed with each other as the study of (Abu Fakhr, 2012) and (Al-Ahmadi, 2018), in that its results were opposite and inconsistent with the results of the current study except nevertheless they agreed with them in terms of recommendations, as they differed with some of the researches in terms of the method used and the type of sample in the study.

\section{Study methodology and procedures:}

\section{Methods and procedures}

This chapter included a description of the study methodology used and the method and procedures that were followed by the researcher, in order to achieve the goals of the study, which is the identification of the role of technical education teachers in developing emotional awareness of students. It also includes a description of the study community, its sample and the method chosen in addition to the method of preparing and developing the study tool that was used and the necessary procedures to verify the validity and reliability of the study tool, study variables and statistical treatments that were used in responding and answering the study questions to know the results of this study.

\section{Study Methodology:}

In order to achieve the objectives of the study, the researcher used the descriptive approach to describe, analyze and interpret the results of the responses of the members of the study sample, as this procedure is the most appropriate for such a study, through the use of the questionnaire that addresses the fields of study as a way to collect data related to the study, and then analyze it in order to reach the results that helps at explaining the phenomenon and answering study questions.

\section{Study Population:}

The study population consisted of students of the primary Jordanian government schools (Eighth, Ninth and Tenth Grade) in the academic year (2020/2019), and their number (43889) male and female, according to the statistics of the Ministry of Education which presented in the end of the academic year of (2018/2019).

\section{The Study Sample:}

This study was applied to a randomly chosen sample from the study population from among the Jordanian public school students (Eighth, Ninth and Tenth Grade) for the academic year (2019/2020), where (450) questionnaires were distributed to them, and (430) questionnaires were retrieved and they represent a percentage $(10 \%)$ of the original study population.

After determining the required sample size that was withdrawn, it must be taking into account the percentage of their distribution in the original population according to the study variables, by following the proportional distribution method for simple random samples as follows:

Table (1)

The study sample is distributed according to gender and grade

\begin{tabular}{|c|c|c|c|}
\hline Study Variables & Variable categories & Frequency & Percentage \\
\hline \multirow{2}{*}{ Gender } & Males & 217 & $50.5 \%$ \\
\hline & Females & 213 & $49.5 \%$ \\
\hline \multirow{3}{*}{ Grade } & 8th Grade & 81 & $18.8 \%$ \\
\hline & 9th Grade & 111 & $25.8 \%$ \\
\hline & 10th Grade & 238 & $55.3 \%$ \\
\hline \multicolumn{2}{|c|}{ Total } & 430 & $100.0 \%$ \\
\hline
\end{tabular}




\section{Study Tool:}

After reviewing the theoretical literature and previous studies on the subject/ topic of the study, the researcher developed a study tool in the form of a questionnaire to measure the role of art education teachers' in developing emotional awareness of students, where the study tool consisted of (28) paragraphs for each in addition to basic demographic information, in addition to the opinions of arbitrators and specialists In this field, some paragraphs have been modified and formulated.

The Likert pentaton scale was used, as five levels were defined as follows (very large (5), large (4), medium (3), few (2), rare (1)) to answer those paragraphs, as the degree (5) a high degree, and grade (1) represents a low degree.

\section{Validating the Study Tool:}

A- The apparent validity of the study tool:

After designing the questionnaire in its initial form, it was presented to a group of arbitrators to verify the apparent honesty of the tool, which numbered (12) arbitrators with expertise and experience from faculty members in Jordanian universities specializing in all departments of arts, assets and educational administration, and the arbitrators were asked to judge the quality of the content of the paragraphs, expressing an opinion on the quality and integrity of the linguistic performance, and the appropriateness of the paragraph for the field that has been listed below the paragraphs, in addition to any other opinions they see appropriate; whether it is omission or addition, or amendment, and the arbitrators have made many observations, while some paragraphs have been modified, approximately ( $80 \%$ ), as a minimum for the agreement between the arbitrators as a criterion for judging the validity of the phrase, and thus the number of paragraphs of the tool after arbitration became composed of (28) paragraphs in its final form.

\section{B - Structural validity of the tool (validation of internal consistency)}

To verify the sincerity of the building, the researcher used the questionnaire tool to measure the role of art education teachers' in developing emotional awareness of students, and to determine the degree of difference between the roles of art education teachers' in developing emotional awareness among students, after confirming the apparent honesty of the study tool, where the researcher applied it.

On a prospective sample consisting of (25) male and female students from outside the study sample in order to identify the extent of the internal consistency of the tool and the extent of the contribution of the constituent parts to it, by calculating the Pearson correlation coefficient; the values of the correlation coefficient of the total degree of the tool, the following table shows that.

Table (2)

Correlation coefficients for the tool of the role of art education teachers' in developing the emotional awareness of students with the overall degree of the tool

\begin{tabular}{|c|c|c|c|c|c|}
\hline $\begin{array}{c}\text { Paragraph } \\
\text { Number }\end{array}$ & $\begin{array}{c}\text { Correlation } \\
\text { Coefficient } \\
\text { Paragraph with } \\
\text { scale } \\
\end{array}$ & $\begin{array}{c}\text { Paragraph } \\
\text { Number }\end{array}$ & $\begin{array}{c}\text { Correlation } \\
\text { coefficient } \\
\text { Paragraph with } \\
\text { scale } \\
\end{array}$ & $\begin{array}{c}\text { Paragraph } \\
\text { Number }\end{array}$ & $\begin{array}{c}\text { Correlation } \\
\text { Coefficient } \\
\text { Paragraph with } \\
\text { scale } \\
\end{array}$ \\
\hline 1 & $0.904 * *$ & 11 & $0.814 * *$ & 21 & $0.687 * *$ \\
\hline 2 & $0.888 * *$ & 12 & $0.836 * *$ & 22 & $0.814 * *$ \\
\hline 3 & $0.699 * *$ & 13 & $0.464 *$ & 23 & $0.819 * *$ \\
\hline 4 & $0.642 * *$ & 14 & $0.909 * *$ & 24 & $791 * *$ \\
\hline 5 & $0.599 * *$ & 15 & $0.614 * *$ & 25 & $0.900 * *$ \\
\hline 6 & $0.646 * *$ & 16 & $0.699 * *$ & 26 & $0.787 * *$ \\
\hline 7 & $0.850 * *$ & 17 & $0.744 * *$ & 27 & $0.490 *$ \\
\hline 8 & $0.814 * *$ & 18 & $0.814 * *$ & 28 & $0.718 * *$ \\
\hline 9 & $0.886 * *$ & 19 & $0.897 * *$ & & \\
\hline 10 & $0.750 * *$ & 20 & $0.750 * *$ & & \\
\hline
\end{tabular}

* Statistically significant at the level $(\alpha=0.01)$.

** Statistically significant at the level $(\alpha=0.05)$. 
Table (1) shows that the values of the correlation coefficients for the total score of the study tool ranged between $(0.464-0.904)$ with the tool as a whole, and all of these values were statistically significant at the level of significance $(\alpha=0.05)$ and this means that there is a degree of validity of the internal consistency In the paragraphs is a tool for the role of art education teachers' in developing emotional awareness of students.

\section{The stability of the study tool:}

To ensure the consistency of the study tool, the stability factor was calculated using the internal consistency method according to the( Cronbach-Alpha) equation, as it measures the consistency in the responses of the study sample individuals on the paragraphs in the questionnaire, where the study tool was applied to a group outside the study sample consisting of (25) male and female students to ascertain their consistency, as the ( CronbachAlpha) stability coefficient for the total sum of the instrument has got all Paragraphs (0.972), and these values are considered good values for the purposes of the current study, in light of what was indicated by previous studies.

\section{Study variables}

\section{First: Independent Variables:}

Estimations of students in Jordanian schools on the paragraphs of the study tool.

\section{Second: Intermediate Variables:}

- Gender: It has two categories: (Male, Female).

- Class/Grade: It has three classes: (Eighth Grade - Ninth Grade - Tenth Grade).

\section{Third: Dependent Variables:}

- Developing emotional awareness of students in Jordanian government schools.

\section{Results}

This chapter aims to present the results that represented the responses of the study members to the tool's paragraphs, after applying the study procedures and analyzing the statistical data collected. The following is a presentation of the study results where this study aims to know the role of art education teachers' in developing the emotional awareness of students, and determining the degree of difference between the roles of teachers of art education in developing emotional awareness of students according to gender and classroom variables, by answering the following questions:

\section{Results Related to Answering the First Question:}

What is the role of art education teachers' in developing the emotional awareness of students from the viewpoint of the students themselves?

In order to answer this question, arithmetic averages, standard deviations, estimation and ranks for the role of art education teachers in developing the emotional awareness of students were extracted from the students' viewpoint themselves for each of the paragraphs separately, and an arrangement was made for the paragraphs of each tool, and Table (3) shows that: 
Table (3)

Arithmetic averages and standard deviations of the paragraphs of a tool for the role of art education teachers' in the development of emotional awareness of students from the viewpoint of the students themselves for each paragraph of paragraphs.

\begin{tabular}{|c|c|c|c|c|c|}
\hline Number & Paragraph & $\begin{array}{l}\text { Arithmetic } \\
\text { Mean }\end{array}$ & Standard Deviation & Evaluation & Rank \\
\hline .1 & $\begin{array}{l}\text { I can imagine beautiful shapes in } \\
\text { my mind. }\end{array}$ & 3.86 & 0.85 & Big / large & 11 \\
\hline .2 & $\begin{array}{l}\text { I can see the beautiful shapes in } \\
\text { the surrounding natural } \\
\text { environment. }\end{array}$ & 4.28 & 0.67 & Very big/large & 1 \\
\hline .3 & $\begin{array}{l}\text { I have knowledge about the history } \\
\text { of arts. }\end{array}$ & 3.13 & 0.98 & Medium & 21 \\
\hline .4 & $\begin{array}{l}\text { I have the ability to know the } \\
\text { degree of consistency of the shapes } \\
\text { in the painting }\end{array}$ & 3.99 & 0.81 & Big / large & 7 \\
\hline .5 & $\begin{array}{l}\text { I can distinguish the boundaries of } \\
\text { shapes in the painting. }\end{array}$ & 3.91 & 0.46 & Big / large & 8 \\
\hline .6 & $\begin{array}{l}\text { I can note the repeated shapes in } \\
\text { the painting. }\end{array}$ & 3.43 & 0.80 & Big / large & 14 \\
\hline .7 & $\begin{array}{l}\text { I can choose the appropriate } \\
\text { materials in various artistic } \\
\text { activities. }\end{array}$ & 3.90 & 0.76 & Big / large & 9 \\
\hline .8 & $\begin{array}{l}\text { I realize the boundaries of the } \\
\text { shape by attaching it to the } \\
\text { background of the painting } \\
\text { (optical illusion) }\end{array}$ & 3.27 & 0.89 & Medium & 15 \\
\hline .9 & $\begin{array}{l}\text { I understand the teacher's } \\
\text { keenness on the interpretation of } \\
\text { some of the paintings. }\end{array}$ & 3.19 & 1.04 & Medium & 18 \\
\hline .10 & $\begin{array}{l}\text { I feel relax in the atmosphere } \\
\text { created by the education inside the } \\
\text { classroom }\end{array}$ & 3.91 & 0.75 & Big / large & 8 \\
\hline .11 & $\begin{array}{l}\text { I am attracted to the attractive style } \\
\text { used by the teacher in the } \\
\text { interpretation of paintings. }\end{array}$ & 3.26 & 0.89 & Medium & 16 \\
\hline .12 & $\begin{array}{l}\text { I prefer to see curved lines in } \\
\text { paintings more than the straight } \\
\text { ones. }\end{array}$ & 3.18 & 1.03 & Medium & 19 \\
\hline .13 & $\begin{array}{l}\text { I have a team spirit when working } \\
\text { with the group. }\end{array}$ & 4.23 & 0.75 & Very big / large & 2 \\
\hline .14 & $\begin{array}{l}\text { I rejoice when I accomplished the } \\
\text { artistic activity which I thought } \\
\text { was difficult. }\end{array}$ & 3.82 & 0.86 & Big / large & 12 \\
\hline .15 & $\begin{array}{l}\text { I rejoice when the teacher praises } \\
\text { my performance of artistic } \\
\text { activities. }\end{array}$ & 4.17 & 0.79 & Big / large & 4 \\
\hline .16 & $\begin{array}{l}\text { I can correct my performance } \\
\text { mistakes when the teacher explains } \\
\text { how to correct them. }\end{array}$ & 3.13 & 0.98 & Medium & 21 \\
\hline .17 & $\begin{array}{l}\text { I stimulate production when the } \\
\text { school gives the opportunity to } \\
\text { make an art exhibition which } \\
\text { presents students' achievements. }\end{array}$ & 3.90 & 0.76 & Big / large & 9 \\
\hline
\end{tabular}




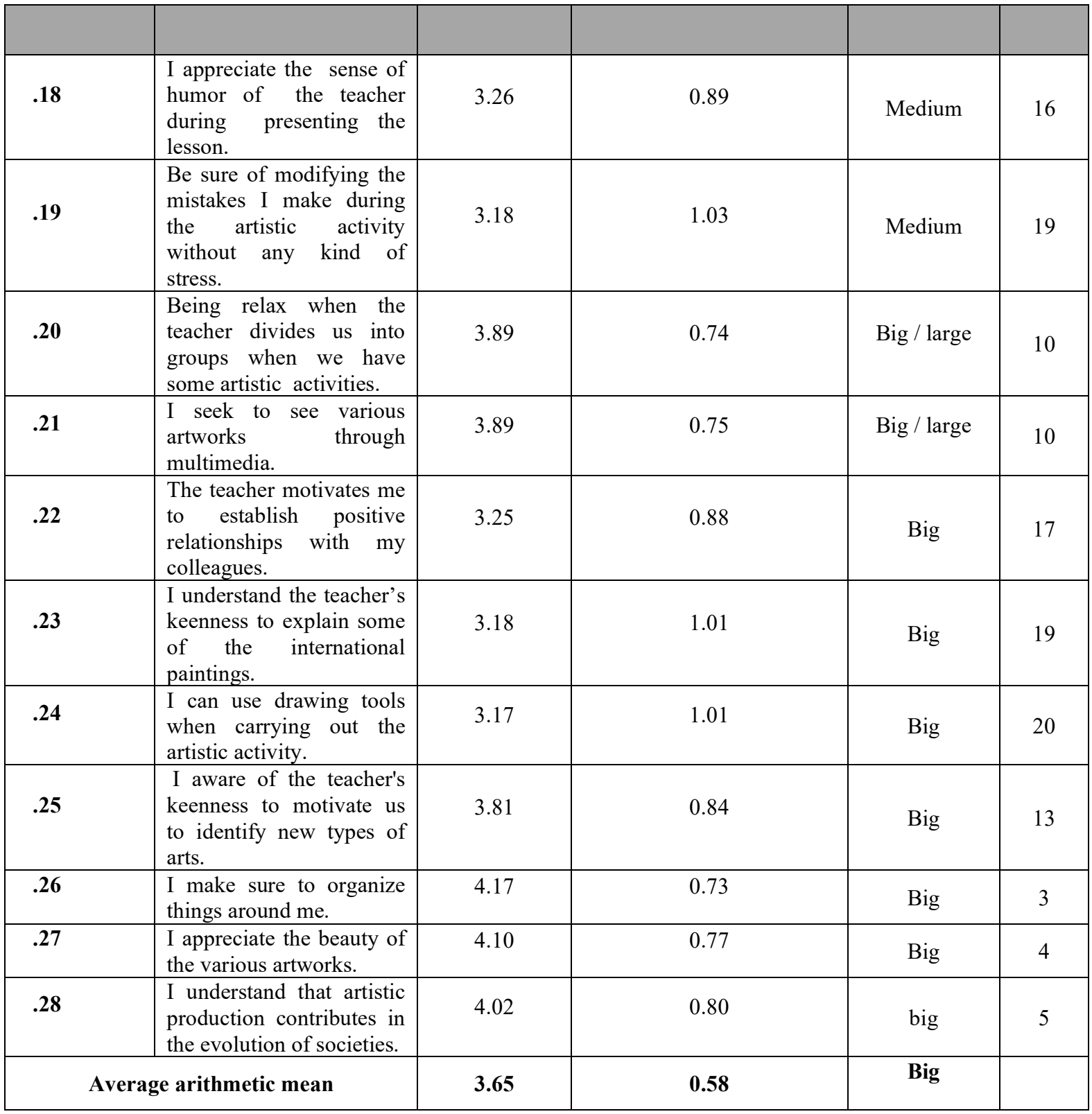

Table (3) shows the arithmetic mean, the standard deviations, and the rank for each of the paragraphs of the tool of the role of teachers of art education in developing the emotional awareness of students from the viewpoint of the students themselves and the arithmetic mean of the tool as a whole, also notes that the arithmetic mean of the paragraphs ranged between $(3.13-4.28)$ and evaluation level between very large to large to medium of the degree of evaluation over the paragraphs, while the overall arithmetic average for the tool as a whole was (3.65) and with a standard deviation (0.58) and the level of a large evaluation degree.

While paragraph (2) came at the first level and stated: "I can notice the beautiful shapes in the surrounding natural environment" with an average of (4.28) and a standard deviation (0.67) with a very large evaluation level. 
Paragraph (13) came second, stating: "The team spirit possesses me when working with the group" with an average score of 4.23 and a standard deviation (0.75) and a very large evaluation level, according to the indicators

The students have a high degree of awareness and specifically the aesthetic awareness through having an intuitive sense and an emotional sense to observe the beautiful shapes in the surrounding environment, which in turn enhances the emotional awareness of them, especially as the students also possess the team spirit when working with the group and these two characteristics; Individually "and" realize the importance of group participation in the work to improve production "; they are those who work to develop collective awareness, which in turn works to savor the topics of beauty and raise the aesthetic sense of individuals.

Paragraph (3) and paragraph (16) came last, as paragraph (3) stated: "I have an understanding of the history of the arts." Paragraph (16) stated: "I can correct my performance mistakes when the teacher explains how to correct it for me." "With an arithmetic average (3.13) and a standard deviation (0.98) and an average evaluation level, and it is noted from the results that in the event that the knowledge awareness of students has been developed by feeding them with varied technical information about the history of the arts, with its theoretical forms as knowledge and the process as an application that develops a sense of aesthetic experience they have got through actual practice of various artistic activities, they will then be able to complete the artworks and their performance in a good way based on the cognitive and emotional aspects in motivating them towards creativity .

Results related to answering the second question:

Are there any statistically significant differences at the level of significance $(0.05=\alpha)$ in the role of art education teachers in developing emotional awareness of students due to gender, classroom changes?

To answer this question, mathematical averages and standard deviations were extracted. The role of technical education teachers in developing emotional awareness among students is attributed to gender and classroom variables. To show the statistical differences between mathematical averages, a T-test was used for independent samples of the gender variable and a monotheistic variance analysis known as (One Way Anova) for the class variable, and the tables below show this.

First: Gender

Table (4)

Mathematical Averages, Standard Deviations, and a " $t$ " Test of the Gender Impact on the Degree of the Role of Art Education Teachers' in Developing the Emotional Awareness of Students.

\begin{tabular}{|c|c|c|c|c|c|c|c|}
\hline Questionnaire & Gender & Number & $\begin{array}{c}\text { Arithmetic } \\
\text { Mean }\end{array}$ & $\begin{array}{c}\text { Standard } \\
\text { Deviation }\end{array}$ & $\begin{array}{c}\text { Value } \\
\text { of "t" }\end{array}$ & $\begin{array}{c}\text { Degrees of } \\
\text { Freedom }\end{array}$ & $\begin{array}{c}\text { Significance } \\
\text { Level }\end{array}$ \\
\hline \multirow{2}{*}{$\begin{array}{c}\text { The tool as a } \\
\text { whole }\end{array}$} & Male & 217 & 3.57 & 0.56 & \multirow{2}{*}{2.968} & 428 & 0.003 \\
\cline { 2 - 8 } & Female & 213 & 3.74 & 0.59 & \multirow{2}{*}{0.968} & \\
\hline
\end{tabular}

It is clear from Table (4) that there are statistically significant differences at the level of statistical significance (= $0.05=\alpha$ ) between the estimation average of the individuals in the sample on the study tool as a whole to the degree of the role of art education teachers' in developing awareness of students due to the difference in gender variable as the statistical value of the test $(\mathrm{t})$ on the total tool (2.968)

At the significance level $(0.003)$, this value is statistically significant at $(0.05=\alpha)$, where the differences were in favor of the female group with an average score of (3.74) compared to the male group with a mean (3.57). 
Second: The Class

Table (5)

Arithmetic averages and standard deviations for the role of art education teachers' in developing emotional awareness of students according to the class variable

\begin{tabular}{|c|c|c|c|}
\hline Class & Number & Arithmetic mean & Standard Deviation \\
\hline Eighth Grade & 81 & 3.71 & .53 \\
\hline Ninth Grade & 111 & 3.71 & .62 \\
\hline Tenth Grade & 238 & 3.61 & .58 \\
\hline Sum & 430 & 3.65 & .58 \\
\hline
\end{tabular}

It is noted from Table (5) that there are apparent differences between the averages of the responses of the members of the study sample to the degree of the role of teachers of art education in developing emotional awareness among students according to the variable of the classroom. At the level of significance $(\alpha=0.05)$, and Table (5) shows the results of that, and here it is worth saying that the classroom plays an important role in determining the degree of awareness of students, especially in determining the path of education, as the "tenth grade" is the critical joint for students 'orientation after in the education process, in terms of determining the direction of the future student, either continuing in the academic field, go to vocational education according to his desire, or continuing his academic education according to the field of arts in all of its branches.

Table (6)

Results of a mono-variance analysis of the effect of the class on the degree of the role of art education teachers' in developing emotional awareness of students

\begin{tabular}{|c|c|c|c|c|c|}
\hline Source of Variation & $\begin{array}{c}\text { Sum of } \\
\text { Squares }\end{array}$ & $\begin{array}{c}\text { Degrees of } \\
\text { freedom }\end{array}$ & $\begin{array}{c}\text { Average } \\
\text { Squares }\end{array}$ & Value of F & $\begin{array}{c}\text { Significance } \\
\text { Level }\end{array}$ \\
\hline Between groups & 1.072 & 2 & .536 & & \\
Within groups & 146.224 & 427 & .342 & .565 & .210 \\
\hline Total & 147.296 & 429 & & \\
\hline
\end{tabular}

It is clear from Table (6) that there are no any statistically significant differences at the level of significance $(\alpha=0.05)$ attributed to the effect of the academic class on the degree of the role of art education teachers' in developing emotional awareness of students, where the value of (F) (1.565) at the level of significance is $(0.210)$.

\section{$\underline{\text { Recommendations: }}$}

- Preparing supportive training programs that work on developing and improving a teacher of art education at the professional and personal levels.

-Taking into consideration the need to take care of art education programs and courses through effective educational plans because of their impact on stimulating and raising the degree of awareness among learners.

-Training both the teacher and students in order to develop their technical and artistic skills through the use of technology in their studies and majors to keep pace with modernity and the most prominent techniques in the field of arts.

Adopting effective, realistic and diverse educational strategies and methods to transfer the impact of art education to users. 
- Paying attention to the issue of stimulating productivity for students and teachers together by setting a list of criteria for productive quality that contribute to the preparation and production of artists of different branches of their artistic specialties.

-Paying attention to include instructional methods and programs that develop emotional awareness among students by the school.

- focusing on training all teachers on methods and counseling programs that develop emotional awareness for them.

- shedding light on educating all teachers in the technical field in general and aesthetics in particular and using it in the educational process.

-Doing more studies and researches on the subject of the study

\section{Arabic references:}

Abu Fakhr, Mahran (2012), Quality of the Art Education Teacher Preparation System in the Light of the National Association for Art Education Standards (NAEA), Unpublished Master Thesis, University of Damascus: Syria.

Al Ahmadi, Haifa (2018). The Effect of Using an Electronic Bag to Develop Some Skills of Art Education Teaching Among Primary School Teachers in the Light of Formal Art Education, Journal of Educational Sciences, 1 (1), 1101.

Al Qamash, Qamash (2019). Aesthetics in Organizational Art Education (DBAE) Curriculum and Classroom Practices, Umm Al-Qura University Journal for Educational and Psychological Sciences, 11 (1), 2.

Pam, Robins and Jean Shcot (2000). Emotional Intelligence. Translated by Safaa Al-Asar and Alaa Eddin Kafafi - Cairo - Dar Qabaa for Printing, Publishing and Distribution, p. 72.

Jarrar, Amani (2016). Philosophy of Beauty and Artistic Taste (Education of Aesthetic Sense). Amman: AlYazouri Scientific House for Publishing and Distribution.

Khawaldeh, Mahmoud (2018). Emotional Intelligence, Emotional Intelligence. Amman: Al-Shorouq House for Publishing and Distribution p. 30.

Al-Zahrani, Khaled (2017). The Impact of Web 2.0 Applications on Developing Critical and Artistic Skills Among Middle School Students, Journal of Educational and Psychological Sciences, 1 (1), 26-16.

Shakshak, Anas (2012). Psychological Engineering in Body Management and Personality Formation. Amman: Al-Shorouq House for Publishing and Distribution.

Abdul Hamid, Shaker (1999). Aesthetic Preference. Kuwait: The World of Knowledge (267).

Al-Azazi, Munir (2017). Emotional Programming and Mental Health (Prevention and Development). Amman: Al-Warraq House for Publishing and Distribution.

El-Essawy, Abdel-Rahman (1997). Psychological Awareness. Beirut: al Rateb Universal House, pp. 51-50.

Al-Fahdawi, Saleh (2008). Insufficient Awareness of Cognitive Processes for Students of the Department of Musical Arts, University of Baghdad: College of Fine Arts, available through the site of studies and research in art education: http://www.averroesuniversity.org/pages/SALIHFHADAWY1.htm, retrieved on 1/1/2020.

Qarni, Ezzat (2017). Human (Basic Formation and Major/Big Phenomena). Cairo: The Egyptian General Book Authority, Pp.: 358.

Al-Karkhi, Khansa (2015), The Effect of (Reality Therapy) and (Self-Talk) Styles, Cognitive Guides in developing Emotional Feelings, unpublished doctoral thesis, Diyala University: Iraq. 
Linda, Davidov (2000). Memory (Perception and Awareness). Translated by Safaa Al-Aasar and Alaeddin Kafafi - Cairo - The International House for Cultural Investments, p. 75.

Morsi, Mohamed (2001). Educational Administration, its Origins and Application. Cairo: The World of Books p. 139.

Al-Mazrou, Tahani Bint Abdullah (2018). The Degree of Suitability of the Actual Environment for Art Education to the Specifications of the Classroom Environment in the Light of Systematic Art Education Theory (DBAE) in Middle Schools in the City of Riyadh, International Journal of Educational Studies, 3 (3), 635 647.

Al-Nuseirat, Saleh (2017). Teacher Professional Development. Amman: Al-Shorouq House for Publishing and Distribution.

Al-Hindi, Doaa (2011), Using Dramatic Play in Learning Cognitive Skills and its Effect on Developing Emotional Intelligence, unpublished doctoral thesis, Cairo University: Egypt

\section{Foreign references:}

Sulzer. Deborah Ann. (1998). Supporting the Developing of Self Efficiency in First Year Teacher. University of Central Florida Dissertation Abstracts International. A59\11.

Bahia. S. (2009). "Specificities of Teacher Education in the Fields of Arts and Humanities". Education Sciences Journal. No2. Pp93_102.

Lind. V. (2007). "High Quality Professional Development: An Investigation of the Support for and Barriers to Professional Development in Arts Education". International Journal of Education and Arts. Vol8.No2. Pp1_18.

Yousef. Hussein. (2013). Using Art Education Model From Role Playing Games for Students in Primary School From an Iraq Perspective. University of St 